\title{
Recurrent Urinary Tract Infection from Urethral Mesh Erosion after Midurethral Mesh Sling Surgery
}

\begin{abstract}
Ji-Yeon Han
This paper presents three cases of recurrent urinary tract infections from urethral mesh erosion after transobturator midurethral sling (MUS) surgery. The patients were operated on using a MUS with a mesh for stress urinary incontinence. A few years after surgery ( 0.3 to 7 years), patients complained of recurrent pain in the urethra with voiding symptoms. In all cases, urethrocystoscopy was performed and an erosion of the sling directly across the urethra was found. Patients were managed by dissecting the urethra and removing the mesh via the transvaginal approach under general anesthesia.
\end{abstract}

Department of Urology, Pusan National University Yangsan Hospital, Pusan National University School of Medicine, Busan, Korea

Keywords: Urinary tract infections; Surgical mesh; Urethra; Stress urinary incontinence

Copyright (c) 2019, Korean Association of Urogenital Tract Infection and Inflammation. All rights reserved. (C) (1) This is an open access article distributed under the terms of the Creative Commons Attribution (c) (1) (8) Non-Commercial License (http://creativecommons.org/licenses/by-nc/4.0) which permits unrestricted non-commercial use, distribution, and reproduction in any medium, provided the original work is properly cited.

\author{
Received: 18 April, 2019 \\ Revised: 5 May, 2019 \\ Accepted: 10 May, 2019
}

\author{
Correspondence to: Ji-Yeon Han \\ (iD) https://orcid.org/0000-0002-1695-3100 \\ Department of Urology, Pusan National University \\ Yangsan Hospital, Pusan National University School \\ of Medicine, 20 Geumo-ro, Mulgeum-eup, Yangsan \\ 50612, Korea \\ Tel: +82-55-360-2676, Fax: +82-55-360-2164 \\ E-mail: jyincomo@gmail.com
}

\section{INTRODUCTION}

Midurethral slings (MUS) with a vaginal mesh are an effective treatment modality for SUI with high cure rates ranging from $64-97 \%$ at the $10-y e a r$ follow-up [1-3]. Despite their efficacy in treating SUI, these meshes can be associated with a range of complications. Of these, $0.4-6.7 \%$ of patients developed mesh erosion in a large series [4-7]. Of these complications, however, vaginal extrusion was the most common complication. Despite this, there are few reports and case series of mesh erosion into the urinary tract following sling placement published [8-10]. The precise pathophysiology associated with mesh erosion is not completely understood $[11,12]$. This paper presents three cases of recurrent urinary tract infections from urethral mesh erosion after transobturator MUS surgery.

\section{CASE REPORTS}

\section{Case 1}

A 64-year-old female was operated on with a transobturator (TOT) surgery for stress urinary incontinence (SUI) in 2008. The patient was referred to this hospital because of recurrent pain in the urethra and frequency from six months ago. Urethrocystoscopy was performed and an erosion of the sling directly across the urethra was found (Fig. 1). The urine culture revealed the growth of extendedspectrum beta-lactamase-producing Escherichia coli $>100,000$ colony $/ \mathrm{ml}$. According to the antibiotic susceptibility, ertapenem $1 \mathrm{~g} /$ day was applied preoperatively. The patient was managed by dissecting the urethra and removing the mesh via the transvaginal approach under general anesthesia. Two weeks after surgery, the urethral catheter was removed after cystourethrography. After surgery, the patient showed improvements in the recurrent urinary tract infection and frequency symptoms. No bacteria were observed in the urine 

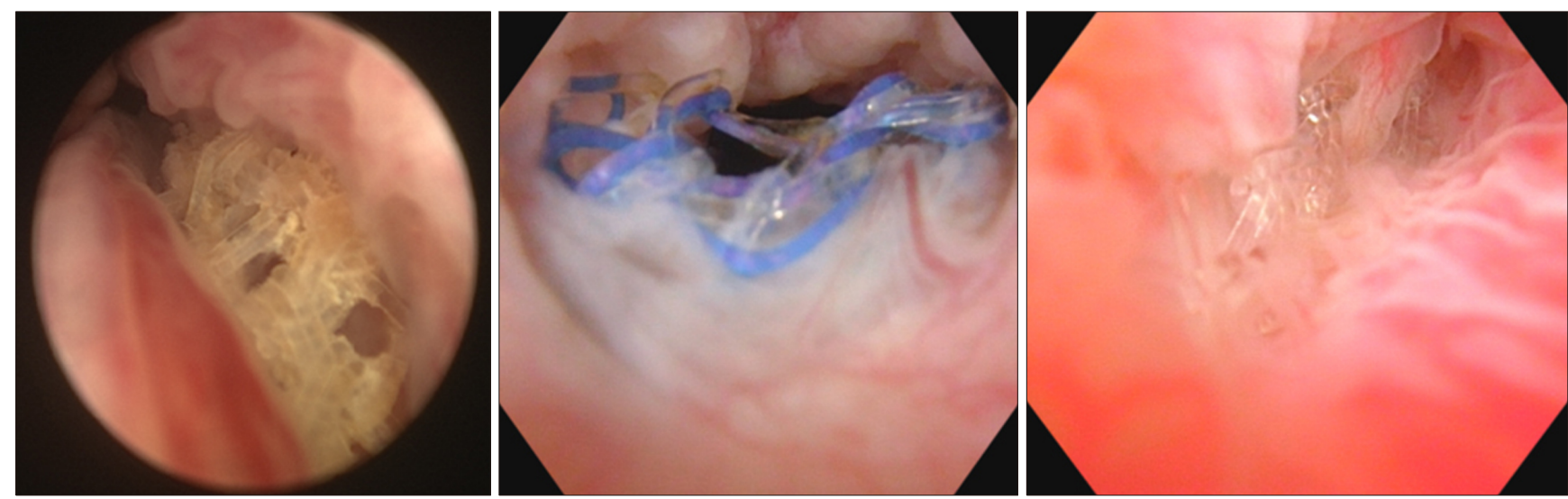

Fig. 1. Mesh erosion in the urethra on urethrocystoscope.

test. Six months after surgery, the patient complained of recurrent pain in the urethra. Urethrocystoscopy revealed a tiny mesh stripe at the 3 o'clock position in the urethra. The second endoscopic management was performed using Holmium laser excision. After a three year follow-up, the mesh was not observed by urethrocystoscopy and the patient had no SUI symptoms.

\section{Case 2}

A 74-year-old female underwent a TOT for SUI. The patient's body mass index (BMI) was 24.2 and she was taking medication for type II diabetes. Seven years after surgery, the patient experienced urgency urinary incontinence (UUI) together with urethral pain. The patient was treated with antibiotics for urethritis, but the symptoms recurred frequently over a one-year period. She was referred to the authors' institution with those symptoms. An urethrocystoscopy revealed urethral mesh erosion. E.coli $>100,000$ colony $/ \mathrm{ml}$ were isolated from the urine culture and sensitive antibiotics were given according to the urine culture. The patient was managed by dissecting the urethra and removing the mesh via the transvaginal approach under general anesthesia. A urethral catheter was applied for two weeks. At the one year follow-up, the mesh was not observed by urethrocystoscopy, but the symptoms of SUI relapsed. Surgery for SUI was recommended, but she did not want further operative treatment.

\section{Case 3}

A 64-year-old female underwent a mini-sling surgery for SUI. Her medical history revealed a BMI of 17.4 and that she had undergone a thyroidectomy and medication for hypercholesterolemia. The patient was referred to the authors' institution with recurrent pain in the urethra during voiding shortly after surgery. Urethrocystoscopy revealed an erosion of the mesh across the urethra. In the urine culture after surgery, Enterococcus faecalis $>100,000$ colony/ml were found and sensitive antibiotics were administered according to the urine culture.

The patient was managed by dissecting the urethra and removing the mesh via the transvaginal approach under general anesthesia. One month after surgery, the patient suffered a relapse of SUI and de novo UUI. No bacteria were observed in the urine test performed after surgery. For the symptoms of SUI, she wanted no further surgical treatment and she was treated with anticholinergics for the overactive bladder symptoms.

\section{DISCUSSION}

A range of factors may influence mesh erosion in the urethra. Factors associated with the pelvic anatomic condition include urogenital atrophy, previous pelvic radiation, prior vaginal surgery, or concomitant procedures, such as hysterectomy and local infection, as well as a high body weight [3,11-13]. The affecting factors associated with the surgical technique include excessive tensioning of the sling and excessively light placement of the mesh in the urethra [8]. Other possible explanations are a lack of vaginal tissue for coverage of the mesh and improper dissecting near the urethra, which might damage the urethral tissue and its vascularity $[11,12,14,15]$. Direct surgical injury to 
the urethra has been suspected as the cause of urethral mesh erosion [16].

The rates of UTI vary widely according to the definition of UTI (symptom-based, treatment-based or cultural-based) or surgical procedure performed (transobturator approach or retropubic approach). Moreover, a low incidence of recurrent UTI has been reported in $0.3-6.4 \%$ of patients after MUS surgery compared to pelvic organ prolapsed surgery $[4,17,18]$.

Recurrent UTI due to mesh erosion to the urinary tract is not frequent but can be treated effectively by surgical correction. Therefore, it is important to diagnose mesh erosion into the urinary tract in patients with recurrent UTI because that problem can be treated effectively by surgical correction. On the other hand, there are no definite guidelines for evaluating patients with recurrent UTI after MUS surgery. For this reason, the diagnosis of mesh erosion may be delayed in real practical conditions and takes time to reach a diagnosis with mesh erosion into the urethra after recurrent UTI.

When mesh erosion into the urethra is suspected, surgical exploration, resection of the mesh fragments, and tissue defect repair are required. Therefore, proper preoperative localization of the mesh fragments and the detection of erosion are important. In general, urethrocystoscopy is the most important tool for making a diagnosis of mesh erosion into the lower urinary tract $[8,19,20]$. Noninvasive pelvic ultrasonography may aid in the identification of urethral erosion and the location of the mesh along the length of the urethra. A study showed that translabial ultrasound might be a good imaging tool for mesh localization and erosion detection in 30 symptomatic women for suspected mesh complications [21]. On the other hand, there is a limitation that this study is a small sized pilot study and experienced sonographers should have a good image for mesh localization. In all cases of this study, translabial ultrasound and transvaginal ultrasound was performed after diagnosis with cystoscopy. Cystoscopy was performed for the diagnosis of mesh erosion into the urethra and translabial ultrasound and transvaginal ultrasound for visualization location of the mesh along the urethra and for deciding the surgical approach. Therefore, in patients with a history of incontinence surgery with vaginal mesh, recurrent UTI with gross hematuria, symptoms of unexplained vaginal or suprapubic pain or new-onset urges or stress incontinence, there should be no hesitation to proceed with urethrocystoscopy.

For urethral erosions, transvaginal urethroplasty was performed to remove the urethral mesh. A study reported the long-term results of transurethral endoscopic excision of the urethra using a Holmium laser [22]. In this study, six out of twelve patients were resolved using that procedure: two with multiple procedures. Six patients required a secondary transvaginal approach, including two small urethrovaginal fistulas. If a regular cystoscope is difficult to work with, a pediatric cystoscope can be used with a clamp and/or scissors alongside the scope to access the mesh to cut it. For larger urethral injuries, reconstructive procedures, including urethra-vaginal fistula repair with a Martius flap, may be required.

This paper presents preventive strategies to reduce mesh erosion-related UTI. Initially, to prevent mesh erosion to the urinary tract, urethrocystoscopy is recommended at the conclusion of every procedure, even if it is a TOT procedure. If the urethra is injured during the procedure, the inserted mesh should be removed and the patient should be allowed to heal with catheter drainage. On the other hand, most surgeons do not perform urethrocystoscopy regularly when inserting a TOT, unlike when performing a retropubic approach. In this case, it is suggested that the use of strategies, such as preprocedure catheter placement to help visualize the urethral injury and check for gross hematuria intraoperatively, may aid in the diagnosis of intraoperative urinary tract injury. During the follow-up, it is important to suspect urethral complications if symptoms, such as urgency, voiding dysfunction, recurrent UTIs, or relapse of SUI, occur after sling procedures. Therefore, the authors recommend investigating the complications related to the mesh through the detailed examination, including the urethrocystoscopy in symptomatic patients. In addition, mesh-related complications can occur early or late [23,24]. In this study, the time from surgery to the onset of symptoms was 0.3 to 7 years. For this reason, patients with a mesh should have a long-term (more than 10 years) follow-up to monitor for complications or a delayed onset of symptoms [25].

In conclusion, although the precise pathophysiology of urethral mesh erosion is not completely understood, the current case underscores the importance of cystourethroscopy, particularly in situations where the patients present with recurrent symptoms of urinary tract in UTI after the 
MUS procedure.

\section{CONFLICT OF INTEREST}

No potential conflict of interest relevant to this article was reported.

\section{REFERENCES}

1. Ford AA, Rogerson L, Cody JD, Aluko P, Ogah JA. Mid-urethral sling operations for stress urinary incontinence in women. Cochrane Database Syst Rev 2017;7:CD006375.

2. Serati M, Braga A, Athanasiou S, Tommaselli GA, Caccia G, Torella $M$, et al. Tension-free vaginal tape-obturator for treatment of pure urodynamic stress urinary incontinence: efficacy and adverse effects at 10-year follow-up. Eur Urol 2017;71: 674-9.

3. Ulrich D, Tammaa A, Holbfer S, Trutnovsky G, Bjelic-Radisic V, Tamussino K, et al. Ten-year followup after tension-free vaginal tape-obturator procedure for stress urinary incontinence. J Urol 2016;196:1201-6.

4. Richter HE, Albo ME, Zyczynski HM, Kenton K, Norton PA, Sirls LT, et al.; Urinary Incontinence Treatment Network. Retropubic versus transobturator midurethral slings for stress incontinence. N Engl J Med 2010;362:2066-76.

5. Cadish LA, West EH, Sisto J, Longoria T, Bebchuk JD, Whitcomb EL. Preoperative vaginal estrogen and midurethral sling exposure: a retrospective cohort study. Int Urogynecol J 2016; 27:413-7.

6. Masata J, Svabik K, Zvara K, Drahoradova P, El Haddad R, Hubka $P$, et al. Randomized trial of a comparison of the efficacy of TVT-O and single-incision tape TVT SECUR systems in the treatment of stress urinary incontinent women--2-year followup. Int Urogynecol J 2012;23:1403-12.

7. Brubaker L, Norton PA, Albo ME, Chai TC, Dandreo KJ, Lloyd $\mathrm{KL}$, et al.; Urinary Incontinence Treatment Network. Adverse events over two years after retropubic or transobturator midurethral sling surgery: findings from the Trial of Midurethral Slings (TOMUS) study. Am J Obstet Gynecol 2011;205:498.e16.

8. Sergouniotis F, Jarlshammar B, Larsson PG. Urethral complications after tension-free vaginal tape procedures: a surgical management case series. World J Nephrol 2015;4:396-405.

9. Morton HC, Hilton P. Urethral injury associated with minimally invasive mid-urethral sling procedures for the treatment of stress urinary incontinence: a case series and systematic literature search. BJOG 2009;116:1120-6.

10. Sweat SD, Itano NB, Clemens JQ, Bushman W, Gruenenfelder J, McGuire EJ, et al. Polypropylene mesh tape for stress urinary incontinence: complications of urethral erosion and outlet obstruction. J Urol 2002;168:144-6.

11. Brophy MM, Klutke JJ, Klutke CG. A review of the tension-free vaginal tape procedure: outcomes, complications, and theories. Curr Urol Rep 2001;2:364-9.

12. Clemens JQ, DeLancey JO, Faerber GJ, Westney OL, Mcguire EJ. Urinary tract erosions after synthetic pubovaginal slings: diagnosis and management strategy. Urology 2000;56:589-94.

13. Petri E, Ashok K. Complications of synthetic slings used in female stress urinary incontinence and applicability of the new IUGA-ICS classification. Eur J Obstet Gynecol Reprod Biol 2012;165:347-51.

14. Daneshgari F, Kong W, Swartz M. Complications of mid urethral slings: important outcomes for future clinical trials. J Urol 2008;180:1890-7.

15. Siegel AL. Urethral necrosis and proximal urethro-vaginal fistula resulting from tension-free vaginal tape. Int Urogynecol J Pelvic Floor Dysfunct 2006;17:661-4.

16. Minaglia S, Oyama IA. Urethral mesh erosion after singleincision mid-urethral sling. Female Pelvic Med Reconstr Surg 2012;18:310-2.

17. Groutz A, Levin I, Gold R, Pauzner D, Lessing JB, Gordon D. "Inside-out" transobturator tension-free vaginal tape for management of occult stress urinary incontinence in women undergoing pelvic organ prolapse repair. Urology 2010;76: 1358-61.

18. Nygaard I, Brubaker L, Chai TC, Markland AD, Menefee SA, Sirls $L$, et al. Risk factors for urinary tract infection following incontinence surgery. Int Urogynecol J 2011;22:1255-65.

19. MacDonald S, Terlecki R, Costantini E, Badlani G. Complications of transvaginal mesh for pelvic organ prolapse and stress urinary incontinence: tips for prevention, recognition, and management. Eur Urol Focus 2016;2:260-7.

20. Chermansky CJ, Winters JC. Complications of vaginal mesh surgery. Curr Opin Urol 2012;22:287-91.

21. Viragh KA, Cohen SA, Raz S, Lo J, Raman SS. Translabial ultrasound in midurethral sling (mesh) visualization and erosion detection in women with stress urinary incontinence: a retrospective pilot study. Ultrasound Q 2018;34:238-44.

22. Wang C, Zimmern PE, Lemack G. Long-term results of transurethral endoscopic excision using the Holmium laser for urethral perforation of synthetic slings. Low Urin Tract Symptoms 2019;11:O103-10.

23. Khanuengkitkong S, Lo TS, Dass AK. Delayed vaginal and urethral mesh exposure: 10 years after TVT surgery. Int Urogynecol J 2013;24:519-21.

24. Dwyer PL, Riss P. The mesh debate. Int Urogynecol J 2012; 23:1-2.

25. Lee D, Zimmern PE. Management of complications of mesh surgery. Curr Opin Urol 2015;25:284-91. 